\title{
Predicting the solid solubility limit in high-entropy alloys using the molecular orbital approach
}

\author{
Saad Sheikh, Uta Klement, and Sheng Guo ${ }^{\text {a) }}$ \\ Surface and Microstructure Engineering, Department of Materials and Manufacturing Technology, \\ Chalmers University of Technology, Gothenburg 41296, Sweden
}

(Received 9 September 2015; accepted 31 October 2015; published online 17 November 2015)

\begin{abstract}
High-entropy alloys (HEAs) are currently at the research frontier of metallic materials. Understanding the solid solubility limit in HEAs, such a highly concentrated multicomponent alloy system, is scientifically intriguing. It is also technically important to achieve desirable mechanical properties by controlling the formation of topologically or geometrically closed packed phases. Previous approaches to describe the solid solubilities in HEAs could not accurately locate the solubility limit and have to utilize at least two parameters. Here, we propose to use a single parameter, the average energy of d-orbital levels, $M d$, to predict the solid solubility limit in HEAs. It is found that $M d$ can satisfactorily describe the solid solubilities in fcc structured HEAs containing $3 \mathrm{~d}$ transition metals, and also in bcc structured HEAs. This finding will greatly simplify the alloys design and lends more flexibility to control the mechanical properties of HEAs. When $4 \mathrm{~d}$ transition metals are alloyed, $M d$ alone cannot describe the solid solubility limit in fcc structured HEAs, due to the large increase of the bond strength that can be gauged by the bond order, $B o$. The potential opportunities and challenges with applying the molecular orbital approach to HEAs are discussed. (C) 2015 AIP Publishing LLC. [http://dx.doi.org/10.1063/1.4935620]
\end{abstract}

\section{INTRODUCTION}

High entropy alloys (HEAs), or multi-principal-element alloys, emerge in recent years as a new category of metallic materials. ${ }^{1-3}$ HEAs represent a ground breaking alloy design strategy in that there exist more than one or two principal elements in these alloys, fundamentally different to the situation in conventional alloys, where, for example, Fe dominates in steels, and $\mathrm{Ti}$ and $\mathrm{Al}$ are the two principal elements in TiAl-based intermetallics. The new alloy design concept intrigued great interest from researchers in the materials, metallurgy, and even condensed matter physics field, as it leads to an enormously unexplored compositional space, and potentially new materials with new structural and functional properties. During the last decade, the research towards HEAs has gradually become the frontier of advanced metallic materials, with more new alloy systems being developed, and more exciting mechanical and functional properties being discovered. $^{4-9}$ Particularly, HEAs are widely regarded as very promising for becoming the new generation of high-temperature materials, mainly due to their compositional flexibility to improve the oxidation and corrosion resistance, and their excellent softening resistance and sluggish diffusion kinetics, $6,7,10,11$ at elevated temperatures. Having said that, however, HEAs are not yet to be able to replace current high-temperature materials, since in most of the HEA systems, the conflict between strength and ductility formulates the bottleneck for their engineering applications, ${ }^{12,13}$ and the high materials cost (high purity is normally required, and a large amount of basically all constituent elements) and high densities are also serious concerns. ${ }^{8}$ Essentially, the difficulties that are encountered by HEAs are

\footnotetext{
a) Author to whom correspondence should be addressed. Electronic mail: sheng.guo@chalmers.se
}

all related to the alloy design strategy in HEAs: know how to choose suitable constituent elements for desired phase constitution and the appropriate amount of them, and to replace expensive/heavier elements with cheaper/lighter elements if their effect can be comparable.

The phases formed in HEAs tend to be simple multicomponent solid solutions, as the solid solutions are stabilized by the high entropy of mixing (this is how HEAs get their name) at high temperatures, and they can be easily frozen to the room temperature when prepared by solidification, ${ }^{1,11}$ the most commonly used method to prepare HEAs at the moment. In most cases, the formed solid solutions are of fcc and bcc structure, and a mixture of them, ${ }^{6,11}$ although in some cases other structured solid solutions also form. ${ }^{14-16}$ Fcc structured HEA solid solutions are known to be quite ductile, but their strength is low; bcc structured HEAs are much stronger, but quite often this high strength is accompanied by the brittleness, particularly under tension. This above mentioned conflict is still a big challenge to be tackled for the engineering application of HEAs. From the alloy design point of view, the formation of fcc or bcc solid solutions in HEAs can now be reasonably controlled by tuning the valence electron concentration $(V E C),{ }^{13}$ where adding elements of higher $V E C$ can favor the fcc solid solutions, while adding element of lower $V E C$ tends to favor the bcc solid solutions. However, the VEC rule is only valid when the alloying products are solid solutions: although the high mixing entropy is quite effective in stabilizing the formation of solid solutions, it cannot exclude the formation of intermetallic compounds, and in some conditions amorphous phases can also form. ${ }^{17-20}$ The current alloy design strategies to control the formation of solid solutions, intermetallics, and amorphous phases are essentially inherited from those used 
historically for binary solid solutions and metallic glasses, i.e., utilizing the atomic size mismatch, the mixing enthalpy, the electronegativity, variations or combinations of them, etc. $^{21}$ Out of various parametric alloy design guidelines, a two-parameter $\delta$ - $\Delta H_{\text {mix }}$ approach is widely used in the HEA community, ${ }^{19,22}$ where $\delta$ describes the atomic size mismatch $\left(\delta=\sqrt{\sum_{i=1}^{n} c_{i}\left(1-r_{i} / \sum_{j=1}^{n} c_{j} r_{j}\right)^{2}}, n\right.$ is the number of alloying elements, $c_{i}$ is the atomic percentage for the $i$ th element, $r_{i}$ or $r_{i}$ is the atomic radius for the $i$ th or jth element), and $\Delta H_{m i x}$ is the averaged mixing enthalpy $\left(\Delta H_{m i x}=\sum_{i=1, j>i}^{n} 4 \Delta H_{A B}^{m i x} c_{i} c_{j}\right.$, $\Delta H_{A B}^{m i x}$ is the enthalpy of mixing for the binary equiatomic $\mathrm{AB}$ alloys). The $\delta-\Delta H_{\text {mix }}$ approach (and also some other parametric approaches) can quite reasonably delineate the formation of solid solutions, intermetallic compounds, and amorphous phases in HEAs merely from given alloy compositions: ${ }^{19,21}$ solid solutions form when $\delta$ is small and $\Delta H_{m i x}$ is not significantly negative, and almost on the opposite amorphous phases form at large $\delta$ and quite negative $\Delta H_{m i x}$, although the formation of amorphous phases is also known to depend on the kinetic factors. Intermetallic compounds form in the intermediate conditions in terms of $\delta$ and $\Delta H_{m i x}$, or in other words, there exists an overlapping region in the twodimensional $\delta$ - $\Delta H_{m i x}$ map where both solid solutions and intermetallics can form, and both intermetallics and amorphous phases can form. ${ }^{19}$ There is certainly a need to avoid such an overlapping between solid solutions and intermetallics from the alloy design point view. On the one hand, it relates to the more strict definition of what HEAs are, ${ }^{23}$ and on the other hand, from at least the mechanical properties perspective, it is desirable to be able to control the formation of intermetallic compounds, particularly topologically closed-pack (TCP) phases and geometrically closed-pack (GCP) phases, since these TCP and GCP phases have been known to play a critical role in strengthening or embrittling conventional alloys. ${ }^{24}$

The search for new guidelines to distinguish the formation of solid solutions and intermetallic compounds, and more specifically, the TCP and GCP phases, constitutes the motivation and target of this work. Alternatively, it can be said that we aim to locate the solid solubility limit in HEAs. We intend to explore the possibility of using the parameter $M d$, the average energy level of the $d$ orbitals of the alloying transition metals, ${ }^{25,26}$ an effective parameter to predict the phase boundary between solid solutions and TCP/GCP phases in transition-metal-based alloys such as Ni-based, Co-based, and Fe-based alloys, to delineate the solid solubility in HEAs. An obvious reason for trying this parameter is because HEAs normally comprise mainly transition metals. In Secs. II-V, we will first give a brief introduction to the Md method and its success in non-HEAs, and then apply this parameter to test its usefulness for the prediction of solid solubility in fcc and bcc structured HEAs, before some discussions and the final conclusion are made.

\section{THE Md METHOD}

The parameter $M d$ and its application to the estimation of solid solubility are clearly introduced in a seminal paper by Morinaga et al. ${ }^{25}$ There were several motivations behind this relatively new parameter at the time when it was proposed: using the electronegativity and atomic size mismatch (by Hume-Rothery et al. $^{27}$ and Darken and Gurry ${ }^{28}$ ) and the electron vacancy numbers of the $\mathrm{d}$ bands (the so-called PHACOMP method by Decker ${ }^{29}$ ) encountered many problems when addressing to alloy systems containing transition metals; the electronegativity and the atomic size parameters are not independent of each other; the electron vacancy number does not include a reflection of the atomic size factor; and also very importantly, the use of only one parameter, instead of more parameters, is quite appealing. Morinaga et al. also critically pointed out that in previous methods to estimate the solid solubilities, the alloying effect and the nature of the second-phase precipitates were not considered, and features associated with the transition metals should be taken into consideration when designing new parameters. The parameter $M d$, a d-electron parameter, was then proposed to estimate the solubility limit of terminal solid solutions in transition-metal-based alloys (the new PHACOMP $\operatorname{method}^{30}$ ), on the basis of discrete-variational DV-X $\alpha$ molecular orbital method for calculations of the electronic structure and properties of molecules. ${ }^{26}$ The d-orbital energy level of an alloying transition metal, $\mathrm{M}$, in a base metal, X, can be obtained from the cluster calculation. For example, in the case of a pure Fe cluster, the levels of $8 \mathrm{e}_{\mathrm{g}}$ to $16 \mathrm{t}_{2 \mathrm{~g}}$ originate mainly from the Fe $3 \mathrm{~d}$ orbitals and form the $\mathrm{Fe} 3 \mathrm{~d}$ band where the Fermi energy level lies. ${ }^{26}$ In the case of an alloyed Fe cluster, new energy levels mainly due to the d-orbitals of the alloying transition metal appear above the Fermi energy level. These levels are called Md levels, and their energy height changes systematically with the order of elements in the periodic table. The Md levels correlate with the electronegativity and the atomic radius of elements in that the $\mathrm{Md}$ levels increase as the electronegativity of the alloying element decreases, and increase with increasing atomic radius of the element. The average energy of these two d-orbital levels, $\mathrm{e}_{\mathrm{g}}$ and $\mathrm{t}_{2 \mathrm{~g}}$, is referred to as $M d$. The $\mathrm{Md}$ values are listed in Table I, for various commonly used transition metals (M) in fcc Ni, bcc Fe, and bcc $\mathrm{Cr}(\mathrm{X}) .{ }^{26,31} \mathrm{It}$ is noted that in Table I, Al and Si are non-transition metals, and their Md values are determined from the interpolation of the curve of $M d$ versus the metallic radius, and therefore, they are only empirical values. The average value of $M d$ for alloys is defined by taking the compositional average, $M d=\sum_{i=1}^{n} c_{i}(M d)_{i}$. When $M d$ increases beyond a critical value, the Md method assumes that the phase instability will occur and that a secondary phase will appear in a terminal solid solution. In other words, a single parameter, the critical $M d$ value determines the solubility limit of the terminal solid solution and also depends on the type of the secondary phase. Also, as the solid solubility changes with the temperature, the critical $M d$ value also depends on the temperature, but the dependence is normally weak. The Md method has been proven quite useful in predicting the phase boundaries of terminal solid solutions in fcc structured Ni-based alloys, Co-based alloys, and Fe-based alloys. $^{25}$ The situation becomes more complicated for bcc 
TABLE I. List of Md and Bo for commonly used transition metals in HEAs. ${ }^{26,31,32}$

\begin{tabular}{|c|c|c|c|c|c|c|c|}
\hline & \multirow{2}{*}{$\begin{array}{c}\text { Element } \\
\mathrm{M}\end{array}$} & \multicolumn{2}{|c|}{$\mathrm{M}$ in $\mathrm{fcc} \mathrm{Ni}$} & \multicolumn{2}{|c|}{$\mathrm{M}$ in bcc $\mathrm{Fe}$} & \multicolumn{2}{|c|}{$\mathrm{M}$ in bcc $\mathrm{Cr}$} \\
\hline & & $\mathrm{Md}(\mathrm{eV})$ & Bo & $\mathrm{Md}(\mathrm{eV})$ & Bo & $\mathrm{Md}(\mathrm{eV})$ & Bo \\
\hline \multirow[t]{8}{*}{$3 \mathrm{~d}$} & $\mathrm{Ti}$ & 2.271 & 1.098 & 2.497 & 2.325 & 2.87 & 5.109 \\
\hline & V & 1.543 & 1.141 & 1.61 & 2.268 & 1.998 & 5.041 \\
\hline & $\mathrm{Cr}$ & 1.142 & 1.278 & 1.059 & 2.231 & 1.301 & 4.938 \\
\hline & $\mathrm{Mn}$ & 0.957 & 1.001 & 0.854 & 1.902 & 0.752 & 4.801 \\
\hline & $\mathrm{Fe}$ & 0.858 & 0.857 & 0.825 & 1.761 & 0.694 & 4.548 \\
\hline & Co & 0.777 & 0.697 & 0.755 & 1.668 & 0.658 & 4.496 \\
\hline & $\mathrm{Ni}$ & 0.717 & 0.514 & 0.661 & 1.551 & 0.213 & 4.276 \\
\hline & $\mathrm{Cu}$ & 0.615 & 0.272 & 0.637 & 1.361 & -0.346 & 4.123 \\
\hline \multirow[t]{3}{*}{$4 d$} & $\mathrm{Zr}$ & 2.944 & 1.479 & 3.074 & 2.551 & 3.359 & 5.475 \\
\hline & $\mathrm{Nb}$ & 2.117 & 1.594 & 2.335 & 2.523 & 2.662 & 5.403 \\
\hline & Mo & 1.55 & 1.611 & 1.663 & 2.451 & 1.968 & 5.286 \\
\hline \multirow[t]{4}{*}{$5 d$} & $\mathrm{Hf}$ & 3.02 & 1.518 & 3.159 & 2.577 & 4.518 & 5.517 \\
\hline & $\mathrm{Ta}$ & 2.224 & 1.67 & 2.486 & 2.57 & 3.605 & 5.471 \\
\hline & W & 1.655 & 1.73 & 1.836 & 2.512 & 2.768 & 5.368 \\
\hline & $\mathrm{Re}$ & 1.267 & 1.692 & 1.294 & 2.094 & 2.037 & 5.221 \\
\hline \multirow[t]{2}{*}{ others } & $\mathrm{Al}$ & 1.9 & 0.533 & $1.034^{\mathrm{a}}$ & $\ldots$ & $1.034^{\mathrm{b}}$ & $\ldots$ \\
\hline & $\mathrm{Si}$ & 1.9 & 0.589 & 1.034 & 0 & $1.034^{\mathrm{b}}$ & $\ldots$ \\
\hline
\end{tabular}

${ }^{\mathrm{a}} \mathrm{Md}$ for $\mathrm{Al}$ in bcc Fe cannot be found. The same $M d$ value of 1.034 for Si was assumed for $\mathrm{Al}$, as $M d$ for $\mathrm{Al}$ and $\mathrm{Si}$ in fcc $\mathrm{Ni}$ are determined from interpolation of the curve of $M d$ vs. metallic radius, and they are of the same value. ${ }^{\mathrm{b}} \mathrm{No}$ values of $M d$ for $\mathrm{Al}$ and $\mathrm{Si}$ in bcc $\mathrm{Cr}$ can be found. The same $M d$ values for $\mathrm{Al}$ and $\mathrm{Si}$ in bcc Fe were then assumed for them in bcc $\mathrm{Cr}$.

structured alloys though, where another alloying parameter, bond order, $B o,{ }^{26}$ which can also be obtained from the cluster calculation, has to be also considered. $B o$ is a measure of the strength of the covalent bond between $\mathrm{M}$ and $\mathrm{X}$ atoms, and $B o$ also changes according to the position of elements in the periodic table (a list of $B o$ for various elements in fcc Ni, bcc $\mathrm{Fe}$, and bcc $\mathrm{Cr}$ is given in Table I). The main reason for the complication in bcc alloys is due to the more significant second-nearest-neighbor interaction, and shorter secondnearest-neighbor interatomic distance that is only $15 \%$ larger than the first-nearest-neighbor distance, while in fcc alloys this distance is $41 \%$ larger and hence the second-nearestneighbor interactions are much less significant. The description of solid solubilities in bcc structured $\mathrm{Fe}$ and $\mathrm{Cr}$ alloys using $M d$ and $B o$ were discussed in Refs. 31 and 32. In all previous efforts to correlate $M d$ (and $B o$ ) with the solid solubilities, the context was set to terminal solid solutions. Can the Md method be extended to highly concentrated alloys, such as HEAs? And more importantly and more interestingly, can it solve the inadequate capabilities of current alloy design approaches, such as the two-parameter $\delta-\Delta H_{\text {mix }}$ plot, to accurately delineate the solid solubilities, or the phase boundaries between solid solutions and intermetallic compounds, in HEAs? Below we will apply the Md method to fcc and bcc structured HEAs, and test how it works in these concentrated alloy systems. $B o$ is not the focus of this work, and we only mention $B o$ when it is helpful for the discussion.

\section{Md AND SOLID SOLUBILITIES IN HEAs}

To test the effect of the parameter $M d$ on predicting the phase boundaries between solid solutions and TCP/GCP
TABLE II. Phase constitutions in fcc structured HEAs containing $3 \mathrm{~d}$ transition metals only, together with their mixing enthalpy, $\Delta H_{m i x}$, atomic size mismatch, $\delta$, and d-orbital energy level, $M d$.

\begin{tabular}{|c|c|c|c|c|c|}
\hline Alloy system & Phase & $\underset{\left(\mathrm{kJ} \cdot \mathrm{mol}^{-1}\right)}{\Delta \mathrm{H}_{\text {mix }} /}$ & $\delta * 100$ & $\mathrm{Md}$ & Reference \\
\hline $\mathrm{CoCrCuFeNi}$ & fcc & 3.20 & 1.03 & 0.822 & 34 \\
\hline $\mathrm{CoCrCu}_{0.5} \mathrm{FeNi}$ & fcc & 0.49 & 0.83 & 0.845 & 37 \\
\hline $\mathrm{CoCrFeMnNi}$ & fcc & -4.16 & 3.27 & 0.89 & 2 \\
\hline $\mathrm{CoCrFeNi}$ & fcc & -3.75 & 0.30 & 0.874 & 38 \\
\hline $\mathrm{CoCrCuFeNiTi}_{0.5}$ & fcc & -3.70 & 4.81 & 0.954 & 39 \\
\hline $\mathrm{Al}_{0.3} \mathrm{CoCrCuFeNi}$ & fcc & 0.16 & 3.42 & 0.883 & 34 \\
\hline $\mathrm{Al}_{0.5} \mathrm{CoCrCuFeNi}$ & fcc & -1.52 & 4.16 & 0.92 & 34 \\
\hline $\mathrm{CoCrCuFeMnNi}$ & fcc & 1.44 & 2.99 & 0.844 & 2 \\
\hline CoCuFeNiV & fcc & -2.24 & 2.20 & 0.902 & 22 \\
\hline $\mathrm{Al}_{0.25} \mathrm{CoCrCu}_{0.75} \mathrm{FeNi}$ & fcc & -0.71 & 3.24 & 0.886 & 40 \\
\hline $\mathrm{Al}_{0.5} \mathrm{CoCrCu}_{0.5} \mathrm{FeNi}$ & fcc & -4.60 & 4.36 & 0.95 & 40 \\
\hline $\mathrm{Al}_{0.25} \mathrm{CoCrFeNi}$ & fcc & -6.75 & 3.47 & 0.934 & 41 \\
\hline $\mathrm{Al}_{0.375} \mathrm{CoCrFeNi}$ & fcc & -7.99 & 4.11 & 0.961 & 41 \\
\hline $\mathrm{Al}_{0.5} \mathrm{CoCrCuFeNiV} \mathrm{V}_{0.2}$ & fcc & -2.50 & 4.14 & 0.942 & 42 \\
\hline $\mathrm{CoCrFeNiTi}_{0.3}$ & fcc & -8.89 & 4.34 & 0.971 & 43 \\
\hline $\mathrm{CoCrFeNiSi}_{0.05}$ & fcc & -5.49 & 0.88 & 0.886 & 44 \\
\hline $\mathrm{CoCrFeNiSi}_{0.1}$ & fcc & -7.14 & 1.20 & 0.899 & 44 \\
\hline $\mathrm{CoCrFeNiSi}_{0.15}$ & fcc & -8.70 & 1.44 & 0.911 & 44 \\
\hline $\mathrm{CoCrFeNiSi}_{0.25}$ & fcc & -11.62 & 1.80 & 0.934 & 44 \\
\hline $\mathrm{CoCrFeNiTi}_{0.5}$ & fcc $+\sigma+$ Laves $+\mathrm{R}$ & -11.56 & 5.32 & 1.029 & 43 \\
\hline $\mathrm{CoCrCuFeNiTi}_{0.8}$ & fcc+Laves & -6.75 & 5.69 & 1.022 & 39 \\
\hline $\mathrm{CoCrCuFeNiTi}$ & fcc+Laves & -8.44 & 6.10 & 1.063 & 39 \\
\hline $\mathrm{Co}_{1.5} \mathrm{CrFeNi}_{1.5} \mathrm{Ti}_{0.5}$ & $\mathrm{fcc}+\eta$ & -10.74 & 4.87 & 0.978 & 45 \\
\hline $\mathrm{Al}_{0.3} \mathrm{CoCrFeNiTi} i_{0.1}$ & $\mathrm{fcc}+\eta$ & -8.93 & 4.39 & 0.975 & 46 \\
\hline
\end{tabular}

phases in HEAs, we scrutinized a decent number of HEA systems where fcc solid solutions and fcc solid solutions plus $\mathrm{TCP} / \mathrm{GCP}$ phases ( $\sigma$ phase, $\mathrm{R}$ phase, $\mu$ phase, and Laves phase $/ \eta$ phase), and also bcc solid solutions and bcc solid solutions plus TCP phases ( $\sigma$ phase and Laves phase) are formed. All chosen alloys are prepared by the casting route, the most commonly used materials preparation method, to simplify the data interpretation by avoiding the interruption from the material preparation aspect. The chosen alloy systems are listed in Tables II-IV, in the sequence of fcc structured HEAs containing $3 \mathrm{~d}$ elements only (for transition metals), fcc structured HEAs containing also $4 \mathrm{~d}$ elements,

TABLE III. Phase constitutions and d-orbital energy level, $M d$, in fcc structured HEAs containing $4 \mathrm{~d}$ transition metals.

\begin{tabular}{lccc}
\hline \hline Alloy system & Phase & Md & Reference \\
\hline $\mathrm{CoCrFeMo}_{0.3} \mathrm{Ni}$ & fcc & 0.921 & 47 \\
$\mathrm{Al}_{0.3} \mathrm{CoCrFeMo}_{0.1} \mathrm{Ni}$ & fcc & 0.959 & 46 \\
$\mathrm{CoCrFeMo}_{0.5} \mathrm{Ni}$ & fcc $+\sigma$ & 0.949 & 47 \\
$\mathrm{Co}_{1.5} \mathrm{CrFeMo}_{0.5} \mathrm{Ni}_{1.5} \mathrm{Ti}_{0.5}$ & fcc $+\sigma$ & 1.025 & 48 \\
$\mathrm{Co}_{1.5} \mathrm{CrFeMo}_{0.8} \mathrm{Ni}_{1.5} \mathrm{Ti}_{0.5}$ & fcc $+\sigma$ & 1.05 & 48 \\
$\mathrm{CoCrFeMo}_{0.85} \mathrm{Ni}$ & fcc $+\sigma+\mu$ & 0.992 & 47 \\
$\mathrm{CoCrFeNb}_{0.103} \mathrm{Ni}$ & fcc + Laves & 0.905 & 49 \\
$\mathrm{CoCrFeNb}_{0.155} \mathrm{Ni}$ & fcc + Laves & 0.92 & 49 \\
$\mathrm{CoCrFeNb}_{0.206} \mathrm{Ni}$ & fcc + Laves & 0.934 & 49 \\
$\mathrm{CoCrFeNb}_{0.309} \mathrm{Ni}$ & fcc + Laves & 0.963 & 49 \\
$\mathrm{CoCrFeNb}_{0.412} \mathrm{Ni}$ & fcc + Laves & 0.99 & 49 \\
$\mathrm{Co}_{1.5} \mathrm{CrFeMo}_{0.1} \mathrm{Ni}_{1.5} \mathrm{Ti}_{0.5}$ & fcc $+\eta$ & 0.988 & 45 and 48 \\
\hline \hline
\end{tabular}


TABLE IV. Phase constitutions and d-orbital energy level, $M d$, in bcc structured HEAs. Md for elements (M) in both fcc $\mathrm{Fe}$ and bcc $\mathrm{Cr}(\mathrm{X})$ are adopted for the calculation.

\begin{tabular}{lcccc}
\hline \hline Alloy system & Phase & Md (in bcc Fe) Md (in bcc Cr) & Reference \\
\hline $\mathrm{Al}_{3} \mathrm{CoCrCuFeNi}$ & bcc & 0.88 & 0.703 & 34 \\
$\mathrm{AlCoCrCu}_{0.25} \mathrm{FeNi}$ & bcc & 0.856 & 0.726 & 22 \\
$\mathrm{Al}_{1.25} \mathrm{CoCrFeNi}$ & bcc & 0.875 & 0.792 & 50 \\
$\mathrm{Al}_{1.5} \mathrm{CoCrFeNi}$ & bcc & 0.882 & 0.803 & 50 \\
$\mathrm{Al}_{2} \mathrm{CoCrFeNi}$ & bcc & 0.895 & 0.822 & 50 \\
$\mathrm{Al}_{2.5} \mathrm{CoCrFeNi}_{\mathrm{Cl}_{3} \mathrm{CoCrFeNi}}$ & bcc & 0.905 & 0.839 & 50 \\
$\mathrm{Al}_{0.5} \mathrm{CrFe}_{1.5} \mathrm{MnNi}_{0.5}$ & bcc & 0.915 & 0.853 & 50 \\
$\mathrm{CoCrCuFeMnNiSi}_{0.2}$ & bcc & 0.888 & 0.826 & 51 \\
$\mathrm{AlCoCrFeMo}_{0.1} \mathrm{Ni}$ & bcc & 0.806 & 0.561 & 52 \\
$\mathrm{AlCoCrFeNb}_{0.1} \mathrm{Ni}$ & bcc & 0.892 & 0.803 & 53 \\
$\mathrm{AlCoCrFe}_{0.6} \mathrm{Mo}_{0.5} \mathrm{Ni}$ & bcc $+\sigma$ & 0.948 & 0.817 & 54 \\
$\mathrm{AlCoCrFeMo}_{0.5} \mathrm{Ni}$ & bcc $+\sigma$ & 0.939 & 0.903 & 55 \\
$\mathrm{AlCoCrFe}_{1.5} \mathrm{Mo}_{0.5} \mathrm{Ni}$ & bcc $+\sigma$ & 0.93 & 0.8872 & 55 \\
$\mathrm{AlCoCrFe}_{2} \mathrm{Mo}_{0.5} \mathrm{Ni}$ & bcc $+\sigma$ & 0.922 & 0.858 & 55 \\
$\mathrm{AlCo}_{0.5} \mathrm{CrFeMo}_{0.5} \mathrm{Ni}$ & bcc $+\sigma$ & 0.958 & 0.911 & 56 \\
$\mathrm{AlCoCrFeMo}_{0.5} \mathrm{Ni}$ & bcc $+\sigma$ & 0.939 & 0.888 & 56 \\
$\mathrm{AlCo}_{1.5} \mathrm{CrFeMo}_{0.5} \mathrm{Ni}$ & bcc $+\sigma$ & 0.924 & 0.869 & 56 \\
$\mathrm{AlCoCrFeNb}_{0.25} \mathrm{Ni}$ & bcc $+\mathrm{Laves}$ & 0.937 & 0.87 & 54 \\
$\mathrm{AlCoCrFeNb}_{0.5} \mathrm{Ni}$ & bcc $+\mathrm{Laves}$ & 1 & 0.951 & 54 \\
$\mathrm{AlCoCrFeNb}_{0.75} \mathrm{Ni}$ & bcc $+\mathrm{Laves}$ & 1.058 & 1.025 & 54 \\
\hline \hline
\end{tabular}

and bec structured HEAs. The listed phase constitutions are mainly determined by the X-ray diffraction method. For the calculation of $M d$ values in Tables II and III, $M d$ values for various alloying elements $(\mathrm{M})$ in fcc $\mathrm{Ni}(\mathrm{X})^{25,26}$ are used and all chosen alloy systems contain Ni. This can be understood that we treat the solid solubilities in Ni-M pseudo binary systems, where $\mathrm{M}$ here are alloy components other than $\mathrm{Ni}$. According to Morinaga et al., these $M d$ values are less sensitive to the choice of the base element $(\mathrm{X})$ in transition metal based fcc structured alloys, i.e., being they $\mathrm{Ni}, \mathrm{Co}$, or Fe. ${ }^{25}$ All chosen fcc structured alloy compositions that are listed in Tables II and III contain Ni, as otherwise the assumption of Ni-M pseudo binary systems is invalid. However, for bcc structured alloys, $M d$ values are sensitive to the choice of the base element (see Table I). As an example, here we choose two base elements, $\mathrm{Fe}$ and $\mathrm{Cr}(\mathrm{X})$, and the $M d$ values for various elements $(\mathrm{M})$ in both bcc $\mathrm{Fe}$ and bcc $\mathrm{Cr}(\mathrm{X})$ from Table I are used for the calculation in Table IV, and of course all chosen alloys contain both $\mathrm{Fe}$ and $\mathrm{Cr}^{26,31,32} \mathrm{We}$ will show later that the choice of base element does not affect the existence of threshold Md values separating the solid solution and TCP phases, and it is simply a matter of shifting the threshold Md values when choosing different base elements, $\mathrm{Fe}$ or $\mathrm{Cr}$ in this case.

To compare with the two-parameter $\delta-\Delta H_{m i x}$ approach, $\delta$ and $\Delta H_{\text {mix }}$ for fcc structured HEAs containing $3 \mathrm{~d}$ elements only are also listed in Table II. Figure 1 shows the twodimensional $\delta-\Delta H_{\text {mix }}$ plot delineating the phase formation in fcc structured HEAs containing $3 \mathrm{~d}$ elements only. All fcc solid solutions form in the shaded region $(\delta \lesssim 0.066$, $\sim-11.6<\Delta H_{m i x}<3.2 \mathrm{~kJ} / \mathrm{mol}$ ), where it has been shown previously within which solid solution phases can form. ${ }^{19}$ However, TCP and GCP phases can also form in this region,

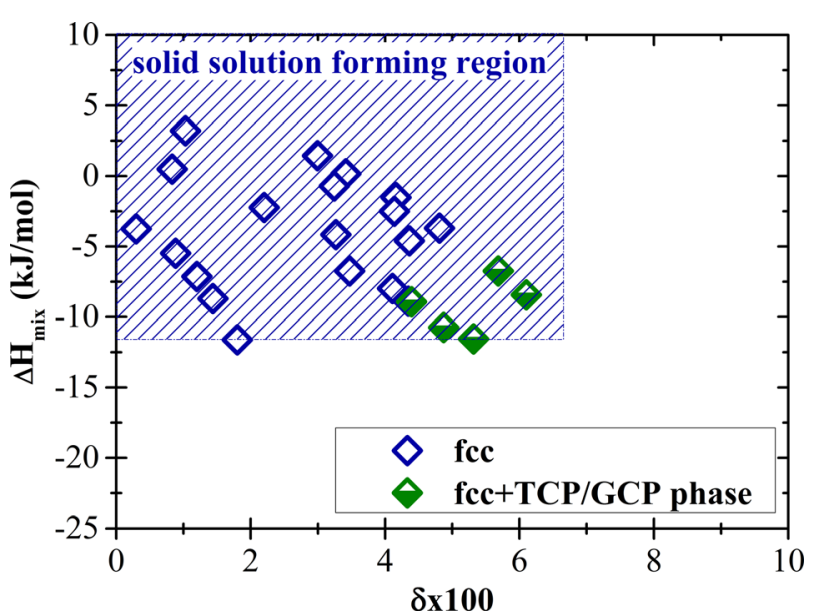

FIG. 1. $\delta-\Delta H_{m i x}$ plot delineating the phase formation in fcc structured HEAs containing $3 \mathrm{~d}$ elements only.

indicating the requirements on $\delta$ and $\Delta H_{m i x}$ are necessary conditions, but not sufficient conditions to form solid solutions in HEAs. This is exactly the motivation for us to search for new parameters to replace the $\delta-\Delta H_{\text {mix }}$ approach, to robustly determine the solid solubility limits in HEAs.

Figure 2 shows the application of the parameter $M d$ to fcc structured HEAs containing $3 \mathrm{~d}$ transition metals (Ti, V, $\mathrm{Cr}, \mathrm{Mn}, \mathrm{Fe}, \mathrm{Co}, \mathrm{Ni}$, and $\mathrm{Cu}$ ) only. Interestingly, there exists a clearly defined critical $M d$ value, $\sim 0.97$, below which only fcc solid solutions form, and beyond which TCP/GCP phases such as the $\sigma$ phase, Laves phase, $\mathrm{R}$ phase and $\eta$ phase will form. This result is certainly exciting, as it shows the possibility of using a simple and single parameter to predict the solid solubility limit in fcc structured HEAs, the most studied HEA systems. The convergence of critical $M d$ values between fcc solid solutions and different TCP/GCP phases is also surprising, as, for example, in terminal solid solutions, the critical Md values vary in different alloy systems. The critical Md for the $\gamma / \sigma$ phase boundaries in Ni-based superalloys is 0.915 , and it is 0.90 in $\gamma / \mu$ phase boundaries in Co-based alloys and in $\gamma / \sigma$ phase boundaries in Fe-based alloys. ${ }^{25}$ The lack of well-defined solvent and solutes, and

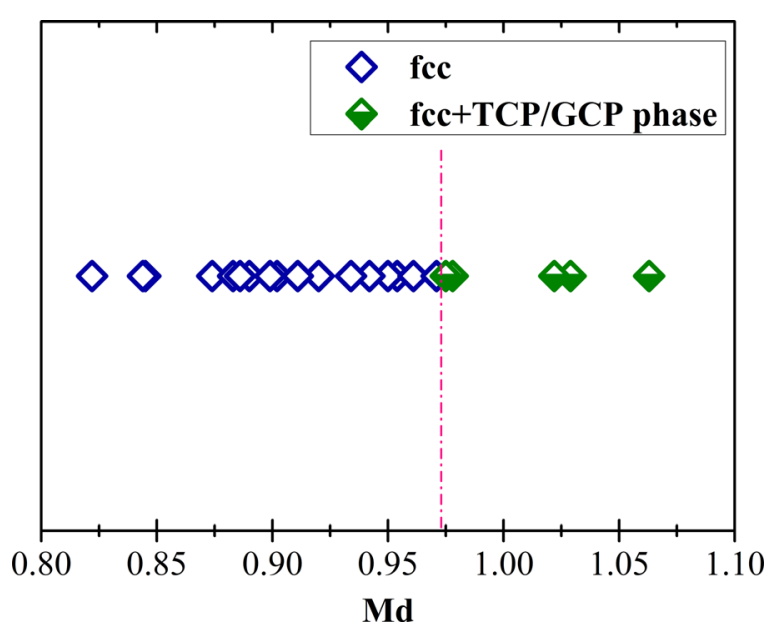

FIG. 2. The parameter $M d$ and the phase formation in fcc structured HEAs containing $3 \mathrm{~d}$ transition metals only. 


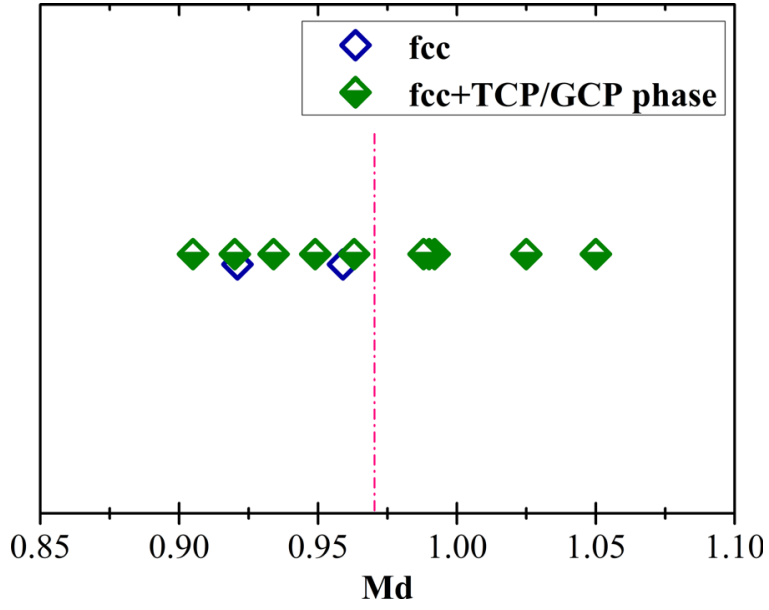

FIG. 3. The parameter $M d$ and the phase formation in fcc structured HEAs containing $4 \mathrm{~d}$ transition metals.

the multi-principal-element nature of solid solutions in HEAs probably render the critical $M d$ in different alloy systems converge to the similar value. The higher critical $M d$ value (0.97) in HEAs, compared to those in conventional alloys, can be understood by the enhanced solid solubility in HEAs and hence the increased compositional average. The situation, however, becomes more complicated when $4 \mathrm{~d}$ transition metals ( $\mathrm{Nb}$ and $\mathrm{Mo}$ ) are alloyed. As seen in Fig. 3, although TCP/GCP phases ( $\sigma$ phase, Laves phase, and $\mu$ phase $/ \eta$ phase) are almost the same as those in the alloys containing $3 \mathrm{~d}$ elements only, a clearly defined phase boundary in terms of $M d$ is not existing. The fcc solid solution seems to still form below the critical $M d$ of 0.97 (the robustness of this argument needs more data to support though), but TCP/GCP phases can form in a wide range of $M d$ values, down to much lower $M d$ than 0.97 . This abnormity can be very possibly connected to the larger bond strength, or $B o$ of $4 \mathrm{~d}$ elements $\mathrm{Nb}$ and $\mathrm{Mo}$ (in fcc Ni, Table I), similar to the situation occurring to bcc alloys. For example, Morinaga et al. showed that the solid solubility in bcc Fe cannot be descried by $M d$ only, and $B o$ has to be taken into consideration. ${ }^{32}$ They also pointed out that a large increase of $B o$ by alloying can lead to the occurrence of more closely packed phases such as the Laves phase, hence restricting the solid solubility. ${ }^{32}$ This scenario is also observed in the fcc structured HEAs containing $4 \mathrm{~d}$ elements, as in almost all those alloys with low solid solubilities (forming TCP phases at low $M d$ ), the Laves phase formed. It can be envisaged that when $5 \mathrm{~d}$ elements, Hf, Ta, and $\mathrm{W}$, are alloyed into fcc structured HEAs, the chances are that the solid solubility in these $5 \mathrm{~d}$ elements containing alloys systems would be low as well, since Hf, Ta, and $\mathrm{W}$ also have large Bo.

Naturally, it would be expected that the parameter $M d$ alone cannot describe the solid solubilities in bcc structured HEAs. ${ }^{32}$ However, very surprisingly, Fig. 4 shows that $M d$ alone can indeed work quite effectively, in both bcc Fe and bcc $\mathrm{Cr}$ (assumed $\mathrm{X}$ ), with different critical $M d$ values of $\sim 0.92$ and $\sim 0.86$, respectively, even when $4 \mathrm{~d}$ elements $\mathrm{Nb}$ and Mo are present. The phase boundaries are between bcc solid solutions and TCP phases, the $\sigma$ phase and the Laves

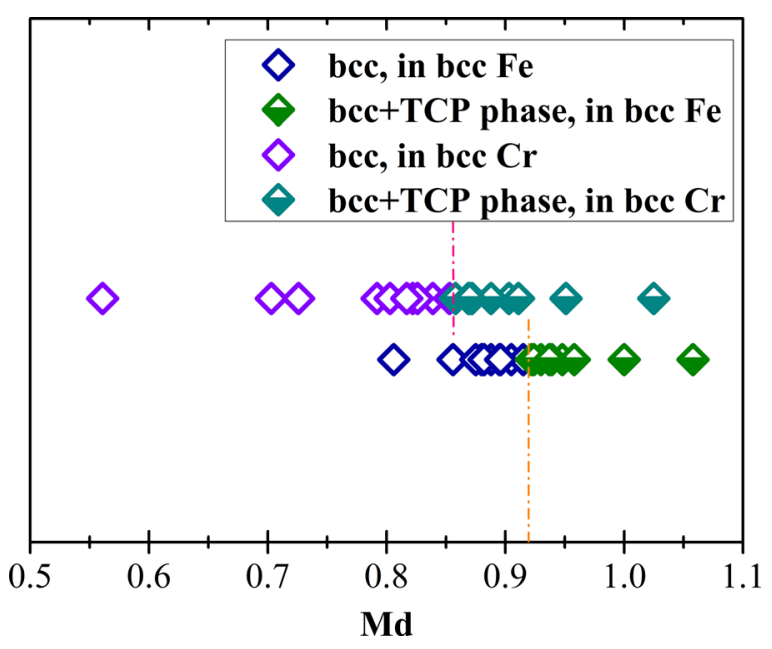

FIG. 4. The parameter $M d$ and the phase formation in bcc structured HEAs. $M d$ for elements (M) in both fcc Fe and bcc $\mathrm{Cr}(\mathrm{X})$ are adopted.

phase. For comparison, the critical $M d$ value to form the Laves phase in Cr-Mo ferritic alloys $(\mathrm{X}=\mathrm{Fe})$ is $\sim 0.85,{ }^{33}$ lower than 0.92 in HEAs. We currently do not have a definite answer to why adding $4 \mathrm{~d}$ elements does not cause any issue, as in the case of fcc structured HEAs containing $4 \mathrm{~d}$ elements. Certainly, this unexpected result will be subject to further inspections when more data are available. However, one note can already be added here. In bcc structured HEAs, the ordering of the bcc phase almost accompanies its formation and quite often, NiAl-like B2 phase $(\beta)$ forms as the result of such ordering. ${ }^{34}$ Morinaga et al. once noted that the Md method cannot only be applied to GCP phase such as $\gamma^{\prime}$ and $\eta$, but also to $\beta$-NiAl $\left(\gamma /(\gamma+\beta)\right.$ phase boundary). ${ }^{25}$ If one considers the formation of $\beta$-NiAl phase as the secondary phase in bcc alloys, then the phase boundaries between bcc solid solutions and intermetallic compounds will definitely be blurred. However, it is practically difficult to tell critically whether $\beta$-NiAl phase forms or not in bcc structured HEAs, from quick structural identification methods like the X-ray diffraction, due to their normally weak superlattice diffraction intensities in HEAs. ${ }^{34}$ Therefore, we made it clear in Fig. 4 that the critical $M d$ values are between bcc solid solutions and TCP phases, and we did not consider the complication by the $\beta$ phase in this case.

\section{DISCUSSION}

\section{A. How about Bo is used together with $M d$ ?}

Previously, it was claimed that the parameter $M d$ needs to be combined with $B o$, to describe the solid solubilities in bcc alloys. Here, in fcc structured HEAs, we also argued that $M d$ alone cannot explain the low solid solubilities in $4 \mathrm{~d}$ elements containing alloy systems, and we ascribed that to the large $B o$ of $4 \mathrm{~d}$ elements. However, this explanation is qualitative in nature and does not offer much quantitative information to account for the solid solubility limit in $4 \mathrm{~d}$ and even $5 \mathrm{~d}$ elements containing HEAs. Will $M d$ together with $B o$ lead to a better prediction? Using again the $4 \mathrm{~d}$ elements containing fcc structured HEAs as an example (Table III), Fig. 5 shows the $M d-B o$ plot for the phase formation in 


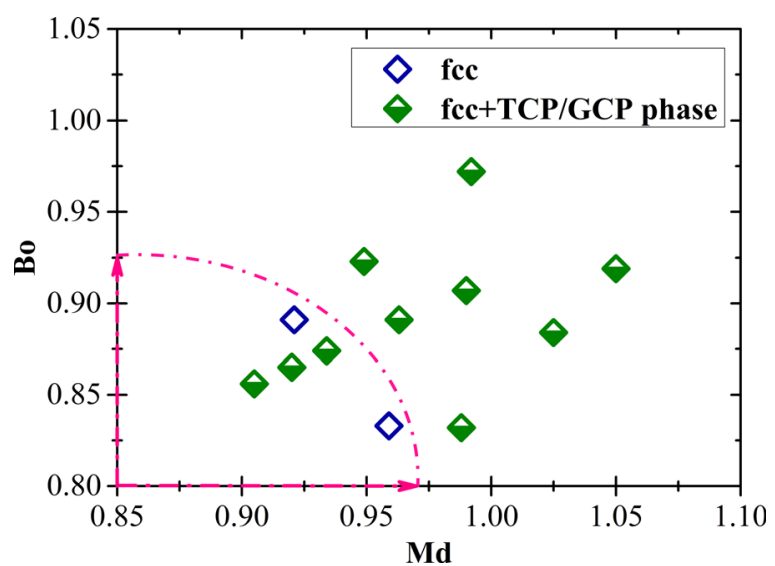

FIG. 5. The $M d$ - Bo plot and the phase formation in fcc structured HEAs containing $4 \mathrm{~d}$ transition metals.

these systems. The dashed-dotted line defined region $(M d<0.97, B o<0.93)$ therefore can be assumed to delineate the solid solubility limit. Comparing Fig. 5 with Fig. 3, the $M d$ - Bo plot does improve the solubility limit prediction by using the parameter $M d$ alone, however, the Laves phase is still seen to form in this region, indicating that the problem is not solved. There remains a challenge on how the molecular orbital approach can be further improved, to account for the difficulty in predicting the solid solubility limit when alloying of $4 \mathrm{~d}$ and $5 \mathrm{~d}$ elements in fcc structured HEAs, and possibly also in bcc structured HEAs, causes the large increase of $\mathrm{Bo}$.

\section{B. The potential of applying the molecular orbital approach to HEAs}

The molecular orbital approach can be of significant importance beyond predicting the solid solubility limit. It can also be used to design alloys with desirable mechanical properties. For example, in commercial cast Ni alloys, the $0.2 \%$ yield strength shows a maximum at $M d: \sim 0.98$ and $B o$ : $\sim 0.67$, the creep strength also shows a maximum around this position, and all of the single crystal superalloys are located near the position. ${ }^{26}$ Every alloy around such a position contains a large volume fraction (about 60\%) of the $\gamma^{\prime}$ phase, without any TCP phase precipitating in it, resulting in the high strength of the alloy. ${ }^{26}$ TUT92 and other secondgeneration single-crystal superalloys, such as PWA 1484 and CMSX-4, are located in a very limited region around $M d$ : 0.985 and $B o: 0.665 .^{26}$ Similarly, the alloy design in HEAs can be correlated with the molecular orbital approach, like the use of $M d-B o$ plot for cast Ni alloys. Such a correlation remains to be established and verified for HEAs. The molecular orbital approach can also be used to guide the modification of alloy compositions in HEAs, by utilizing the equivalence of elements in terms of $M d$ and $B o$. This was exemplified in the modification from PWA 1480, the firstgeneration superalloy, to PWA 1484, the second-generation superalloy. ${ }^{26}$ The $\mathrm{Cr}$ content of PWA 1484 decreases by $6 \mathrm{~mol}$. \%, whereas the Re content increases by $1 \mathrm{~mol}$. \% compared to the respective values of PWA 1480. Further decrease of the $\mathrm{Cr}$ content and corresponding increase of the
Re content lead to René N6, the third-generation superalloy. The molecular orbital approach is thus expected to greatly advance the alloy design in HEAs.

There are a few notes relevant to applying the $M d(B o)$ parameter to HEAs that we want to further clarify here. First, on the choice of base elements and the criterion of Md values, as said in Section III, the choice of base elements has a small effect on the $M d$ values in fcc structured HEAs, and using $\mathrm{Ni}$ as the base element can be a good option, if the target alloy systems contain Ni. In bcc structured HEAs, the choice of different base elements does have a noticeable effect on the $M d$ values, but it does not change the existence of the threshold $M d$ value; it simply shifts the threshold $M d$ value. For example, in Fe-containing bcc structured HEAs, a threshold $M d$ value of 0.92 using $\mathrm{Fe}$ as the base element exits, so when one designs solid solution forming $\mathrm{Fe}$ containing HEAs, one simply designs the $M d$ to be less than 0.92. Similarly, for solid solution forming $\mathrm{Cr}$-containing HEAs, one designs the $M d$ (using $\mathrm{Cr}$ as the base element) to be less than 0.86. As long as one is aware of the choice of the base element ( $\mathrm{Fe}$ or $\mathrm{Cr}$ in this case), and what is the threshold $M d$ value ( 0.92 or 0.86 ) according to the choice of the particular base element, using the $M d$ method to design HEAs is straightforward, and the different threshold $M d$ values are not a concern. Second, for cases beyond what we exemplify here, essentially, our work is providing a methodology, and not giving all solutions, as giving all solutions in one work is almost unlikely. We show examples on how the $M d$ method can be used to design solid solution forming HEAs without the formation of TCP/GCP phases. More specifically, for the fcc structured HEAs case, we use $\mathrm{Ni}$ as the base element and for the bcc case, we use both $\mathrm{Fe}$ and $\mathrm{Cr}$ as base elements. In cases one needs to use the $M d$ method to design new bcc structured HEAs without $\mathrm{Fe}$ and $\mathrm{Cr}$, one cannot use the threshold values of 0.92 or 0.86 anymore, as these two threshold values only work if $\mathrm{Fe}$ or $\mathrm{Cr}$ is present and the assumption of $\mathrm{Fe}-\mathrm{M}$ or $\mathrm{Cr}-\mathrm{M}$ pseudo-binary alloys is therefore valid. Assuming these new bcc structured HEAs contain $\mathrm{Ti}$, such as derivatives of the refractory TaNbHfZrTi alloy, ${ }^{35}$ what one needs to do, when designing bcc solid solution forming refractory alloys, is firstly to find out the threshold $M d$ value from a sizeable database of Ti-containing bcc-structured HEAs, using bcc-Ti as the base element, ${ }^{36}$ then to design the $M d$ to be smaller than this identified threshold $M d$ value. This process is exactly what we exemplify here, and also applies to other HEA systems. We do not use these refractory HEAs to exemplify the application of the $M d$ method to bcc structured HEAs due to two considerations: (1) this work aims to find the phase boundary between the bcc solid solution and TCP phases. There currently lack sufficient data for refractory HEAs (containing the same element that can be assumed as the base element, e.g., Ti) for this purpose, as most reported refractory HEAs are in the bcc solid solution side and not so much in the bcc solid solution plus TCP phase side. Statistically, more data points are required to generate a convincing conclusion; and (2) although $M d$ and $B o$ have been used for the alloy design in Ti-based alloys (not HEAs), the phase boundary is rather between, like bcc-Ti $(\beta$-Ti) and hcp-Ti $(\alpha-\mathrm{Ti})$, than between 
the solid solution and TCP phases. To avoid the unnecessary confusion, we choose to use bcc-Fe and bcc-Cr, rather than bcc-Ti, as the base element for the exemplification purpose. However, how much the $M d$ method can help the alloy design of refractory HEAs is an interesting topic, and we are now working on that direction.

\section{CONCLUSIONS}

Understanding solid solubility limits is critical for the alloy design in HEAs, considering the need to achieve the single-phase solid solution and to control the formation of TCP/GCP phases. In this work, the molecular orbital approach previously applied to describe the solid solubilities in transition-metal-based terminal solutions is first applied to HEAs. It was found that the single parameter $M d$, the dorbital energy level, can well describe the solubility limit in fcc structured HEAs containing $3 \mathrm{~d}$ transition metals only. The critical $M d$ value of 0.97 is higher than that in terminal solid solutions, due to the enhanced solid solubility in HEAs. $M d$ alone, however, cannot describe the solid solubilities in fcc structured HEAs containing $4 \mathrm{~d}$ elements, as alloying of these $4 \mathrm{~d}$ elements will cause a large increase of bond order, $B o$, measuring the strength of covalent bonds. The use of two parameter $M d$ - Bo plot can improve the prediction of solid solubility limit when $4 \mathrm{~d}$ elements are alloyed, but the problem remains and needs further work. Surprisingly, $M d$ alone can describe the solid solubilities in bcc structured HEAs, even when $4 \mathrm{~d}$ elements are present. This statement, however, also needs more data to support, and the complication by the formation of $\beta$-NiAl phase requires further clarification. Overall, the molecular orbital approach offers new opportunities to advance the alloy design in HEAs, although the approach itself needs also to be advanced.

\section{ACKNOWLEDGMENTS}

S.S. and S.G. are grateful for the financial support from Areas of Advance Materials Science from Chalmers University of Technology. S.G. also acknowledges the partial support from the State Key Laboratory for Advanced Metals and Materials Open Fund at University of Science and Technology Beijing (2013-Z04).

${ }^{1}$ J. W. Yeh, S. K. Chen, S. J. Lin, J. Y. Gan, T. S. Chin, T. T. Shun, C. H. Tsau, and S. Y. Chang, Adv. Eng. Mater. 6, 299 (2004).

${ }^{2}$ B. Cantor, I. T. H. Chang, P. Knight, and A. J. B. Vincent, Mater. Sci. Eng. A 375-377, 213 (2004).

${ }^{3}$ S. Ranganathan, Curr. Sci. 85, 1404 (2003).

${ }^{4}$ B. Gludovatz, A. Hohenwarter, D. Catoor, E. H. Chang, E. P. George, and R. O. Ritchie, Science 345, 1153 (2014).

${ }^{5}$ Z. P. Lu, H. Wang, M. W. Chen, I. Baker, J. W. Yeh, C. T. Liu, and T. G. Nieh, Intermetallics 66, 67 (2015).

${ }^{6}$ Y. Zhang, T. T. Zuo, Z. Tang, M. C. Gao, K. A. Dahmen, P. K. Liaw, and Z. P. Lu, Prog. Mater. Sci. 61, 1 (2014).

${ }^{7}$ W. H. Wu, C. C. Yang, and J. W. Yeh, Ann. Chim. Sci. Mater. 31, 737 (2006).

${ }^{8}$ D. B. Miracle, J. D. Miller, O. N. Senkov, C. Woodward, M. D. Uchic, and J. Tiley, Entropy 16, 494 (2014).

${ }^{9}$ J. W. Yeh, Y. L. Chen, S. J. Lin, and S. K. Chen, Mater. Sci. Forum 560, 1 (2007).

${ }^{10}$ K. Y. Tsai, M. H. Tsai, and J. W. Yeh, Acta Mater. 61, 4887 (2013).

${ }^{11}$ C. Ng, S. Guo, J. H. Luan, S. Q. Shi, and C. T. Liu, Intermetallics 31, 165 (2012).
${ }^{12}$ Y. Lu, Y. Dong, S. Guo, L. Jiang, H. Kang, T. Wang, B. Wen, Z. Wang, J. Jie, Z. Cao, H. Ruan, and T. Li, Sci. Rep. 4, 6200 (2014).

${ }^{13}$ S. Guo, C. Ng, J. Lu, and C. T. Liu, J. Appl. Phys. 109, 103505 (2011).

${ }^{14}$ M. Feuerbacher, M. Heidelmann, and C. Thomas, Mater. Res. Lett. 3, 1 (2014).

${ }^{15}$ A. Takeuchi, K. Amiya, T. Wada, K. Yubuta, and W. Zhang, JOM 66, 1984 (2014).

${ }^{16}$ D. Choudhuri, T. Alam, T. Borkar, B. Gwalani, A. S. Mantri, S. G. Srinivasan, M. A. Gibson, and R. Banerjee, Scr. Mater. 100, 36 (2015).

${ }^{17}$ S. Guo and C. T. Liu, Prog. Nat. Sci.: Mater. Int. 21, 433 (2011).

${ }^{18}$ Y. F. Ye, C. T. Liu, and Y. Yang, Acta Mater. 94, 152 (2015).

${ }^{19}$ S. Guo, Q. Hu, C. Ng, and C. T. Liu, Intermetallics 41, 96 (2013).

${ }^{20}$ Z. Wang, Y. Huang, Y. Yang, J. Wang, and C. T. Liu, Scr. Mater. 94, 28 (2015).

${ }^{21}$ S. Guo, Mater. Sci. Technol. 31, 1223 (2015).

${ }^{22}$ Y. Zhang, Y. J. Zhou, J. P. Lin, G. L. Chen, and P. K. Liaw, Adv. Eng. Mater. 10, 534 (2008)

${ }^{23}$ F. Otto, Y. Yang, H. Bei, and E. P. George, Acta Mater. 61, 2628 (2013).

${ }^{24}$ J. R. Davis, ASM Specialty Handbook: Nickel, Cobalt, and Their Alloys (ASM International, Materials Park, OH, 2000).

${ }^{25}$ M. Morinaga, N. Yukawa, H. Ezaki, and H. Adachi, Philos. Mag. A 51, 223 (1985).

${ }^{26} \mathrm{H}$. Adachi, T. Mukoyama, and J. Kawai, Hartree-Fock-Slater Method for Materials Science: The DV-X $\alpha$ Method for Design and Characterization of Materials (Springer, Berlin, 2005).

${ }^{27}$ W. Hume-Rothery, G. W. Mabbott, and K. M. Channel-Evans, Philos. Trans. R. Soc. London A 233, 1 (1934).

${ }^{28}$ L. S. Darken and R. W. Gurry, Physical Chemistry of Metals (McGrawHill New York, 1953), Vol. 1.

${ }^{29}$ R. F. Decker, in Proceedings of Steel Strengthening Mechanims Symposium, Zurich, Switzerland, 1969, p. 1.

${ }^{30}$ M. Morinaga, N. Yukawa, H. Adachi, and H. Ezaki, Superalloys 1984, 523.

${ }^{31}$ Y. Matsumoto, M. Morinaga, T. Nambu, and T. Sakaki, J. Phys.: Condens. Matter 8, 3619 (1996).

${ }^{32}$ M. Morinaga, N. Yukawa, and H. Adachi, J. Phys. F: Metal Phys. 15, 1071 (1985).

${ }^{33}$ H. Ezaki, M. Morinaga, K. Kusunoki, and Y. Tsuchida, J. Iron Steel Inst. Jpn. 78, 1377 (1992).

${ }^{34}$ C. J. Tong, Y. L. Chen, S. K. Chen, J. W. Yeh, T. T. Shun, C. H. Tsau, S. J. Lin, and S. Y. Chang, Metall. Mater. Trans. A 36, 881 (2005).

${ }^{35}$ O. N. Senkov, J. M. Scott, S. V. Senkova, D. B. Miracle, and C. F. Woodward, J. Alloys Compd. 509, 6043 (2011).

${ }^{36}$ G. Bozzolo, R. D. Noebe, and P. B. Abel, Applied Computational Materials Modeling: Theory, Simulation and Experiment (Springer, New York, 2007).

${ }^{37}$ Y. J. Hsu, W. C. Chiang, and J. W. Wu, Mater. Chem. Phys. 92, 112 (2005).

${ }^{38}$ M. S. Lucas, G. B. Wilks, L. Mauger, J. A. Munoz, O. N. Senkov, E. Michel, J. Horwath, S. L. Semiatin, M. B. Stone, D. L. Abernathy, and E. Karapetrova, Appl. Phys. Lett. 100, 251907 (2012).

${ }^{39}$ X. F. Wang, Y. Zhang, Y. Qiao, and G. L. Chen, Intermetallics 15, 357 (2007).

${ }^{40}$ Y. Zhang, G. L. Chen, and L. Gan, J. ASTM Int. 7, JAI102527 (2010).

${ }^{41}$ Y. F. Kao, T. J. Chen, S. K. Chen, and J. W. Yeh, J. Alloys Compd. 488, 57 (2009).

${ }^{42}$ M. R. Chen, S. J. Lin, J. W. Yeh, S. K. Chen, Y. S. Huang, and M. H. Chuang, Metall. Mater. Trans. A 37, 1363 (2006).

${ }^{43}$ T. T. Shun, L. Y. Chang, and M. H. Shiu, Mater. Sci. Eng. A 556, 170 (2012).

${ }^{44} \mathrm{~A}$. Sheikh and S. Guo, unpublished results.

${ }^{45}$ M. H. Chuang, M. H. Tsai, W. R. Wang, S. J. Lin, and J. W. Yeh, Acta Mater. 59, 6308 (2011).

${ }^{46}$ T. T. Shun, C. H. Hung, and C. F. Lee, J. Alloys Compd. 495, 55 (2010).

${ }^{47}$ T. T. Shun, L. Y. Chang, and M. H. Shiu, Mater. Charact. 70, 63 (2012).

${ }^{48}$ Y. L. Chou, J. W. Yeh, and H. C. Shih, Corros. Sci. 52, 2571 (2010).

${ }^{49}$ W. H. Liu, J. Y. He, H. L. Huang, H. Wang, Z. P. Lu, and C. T. Liu, Intermetallics 60, 1 (2015).

${ }^{50}$ C. Li, J. C. Li, M. Zhao, and Q. Jiang, J. Alloys Compd. 504S, S515 (2010).

${ }^{51}$ S. T. Chen, W. Y. Tang, Y. F. Kuo, S. Y. Chen, C. H. Tsau, T. T. Shun, and J. W. Yeh, Mater. Sci. Eng. A 527, 5818 (2010).

${ }^{52}$ L. S. Zhang, Adv. Mater. Res. 750-752, 615 (2013). 
${ }^{53}$ J. M. Zhu, H. M. Fu, H. F. Zhang, A. M. Wang, H. Li, and Z. Q. Hu, Mater. Sci. Eng. A 527, 6975 (2010).

${ }^{54}$ S. G. Ma and Y. Zhang, Mater. Sci. Eng. A 532, 480 (2012).
${ }^{55}$ C. Y. Hsu, T. S. Sheu, J. W. Yeh, and S. K. Chen, Wear 268, 653 (2010).

${ }^{56}$ C. Y. Hsu, W. R. Wang, W. Y. Tang, S. K. Chen, and J. W. Yeh, Adv. Eng. Mater. 12, 44 (2010) 